\title{
MARK TWAIN \\ ADVENTURES \\ OF \\ HUCKLEBERRY \\ FINN
}

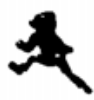





\section{THE MARK TWAIN LIBRARY}

The Library offers for the first time popular editions of Mark Twain's best works just as he wanted them to be read. These moderately priced volumes, faithfully reproduced from the California scholarly editions and printed on acid-free paper, are expertly annotated and include all the original illustrations that Mark Twain commissioned and enjoyed.

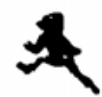

"Huck waited for no particulars. He sprang away and sped down the hill as fast as his legs could carry him." 
Contributing Editors for This Volume

Robert Pack Browning

Anh Q. Bui

Michael B. Frank

Sharon K. Goetz

Kenneth M. Sanderson 


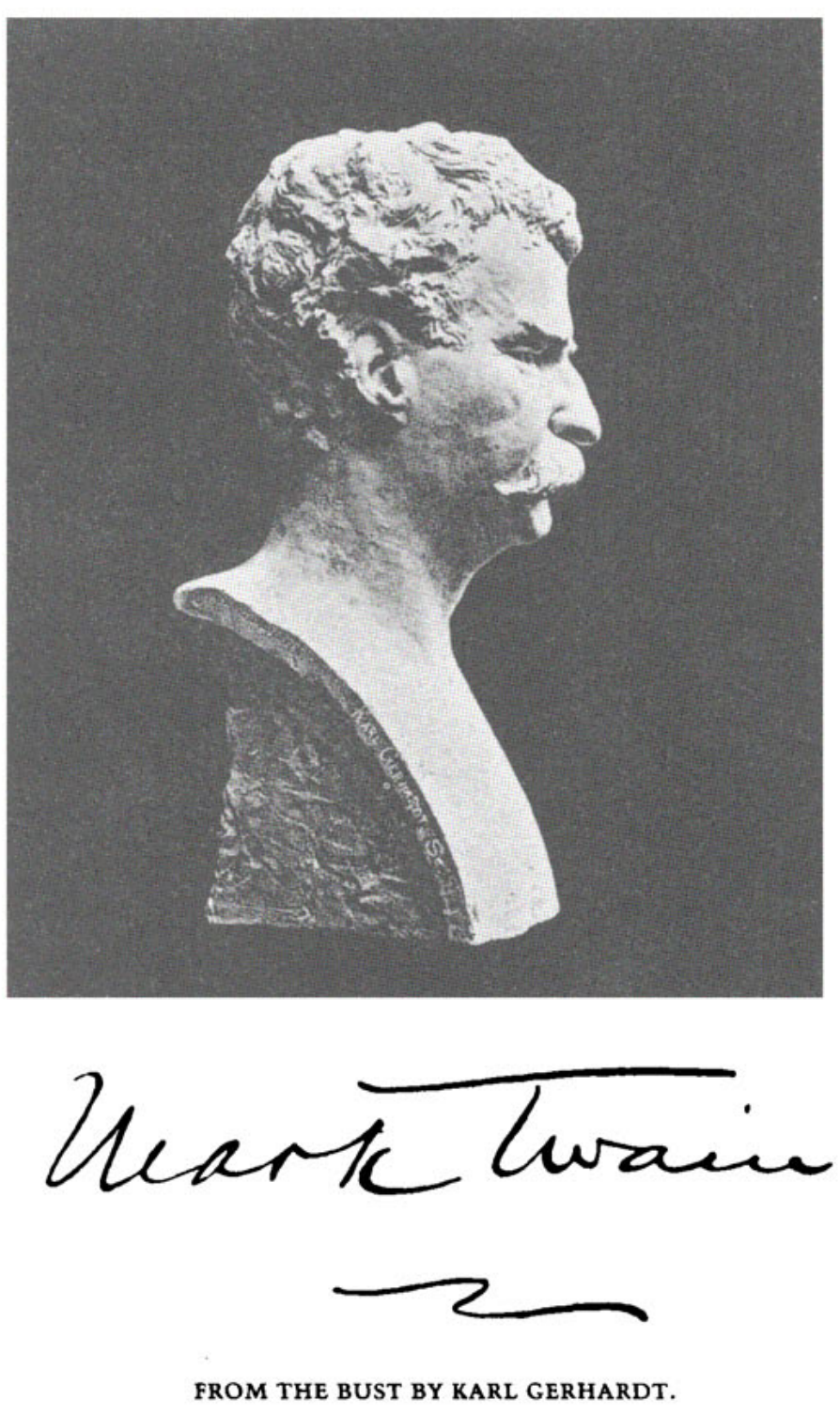




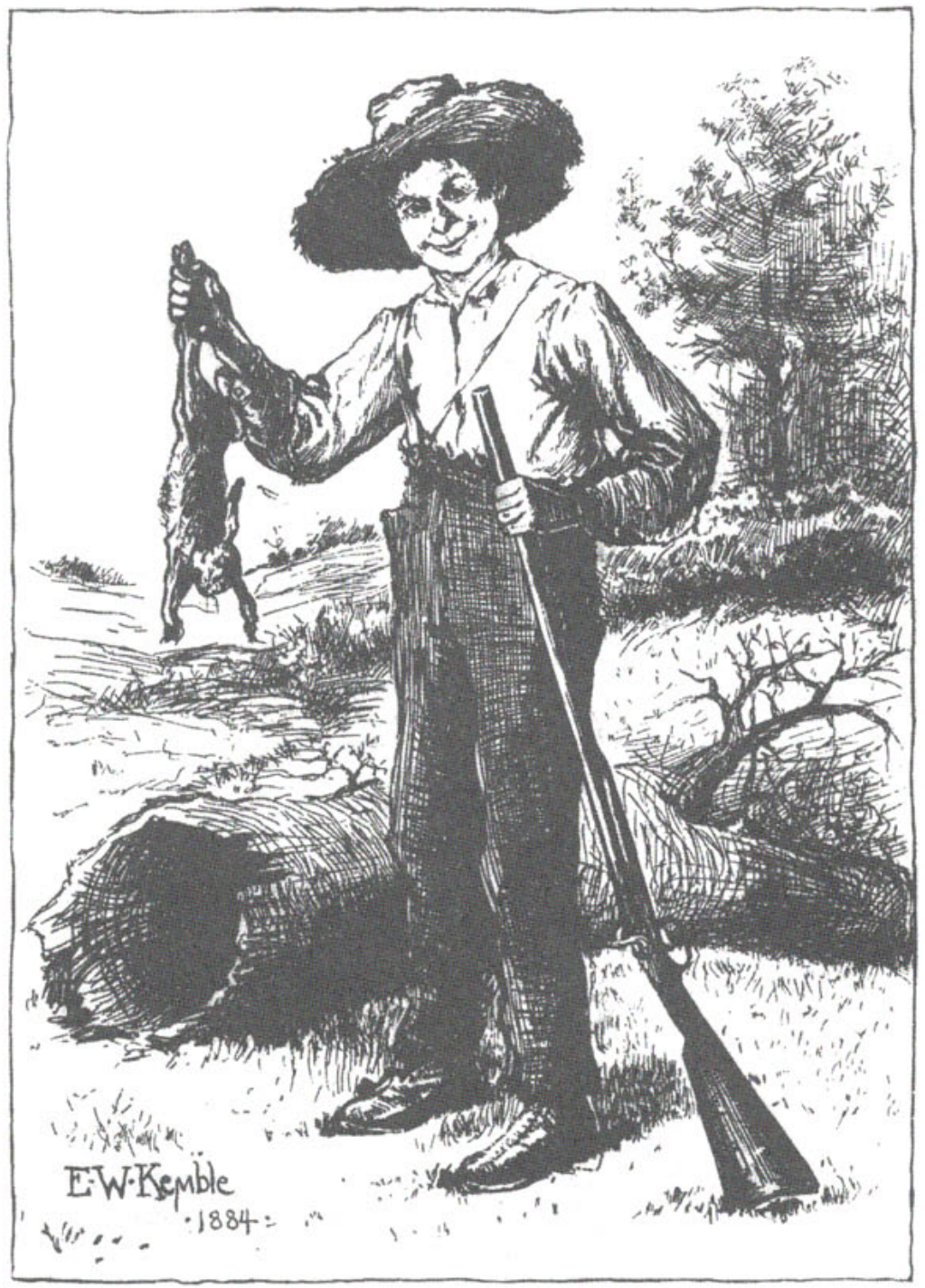

HUCKLEBERRY FINN. 


\section{MARK TWAIN}

\section{ADVENTURES \\ OF \\ HUCKLEBERRY \\ FINN}

TOM SAWYER'S COMRADE

Scene: The Mississippi Valley

Time: ForTy to FifTY YeArs Ago

Illustrated by E. W. Kemble and John Harley

125th Anniversary Edition

\section{Editors}

Victor Fischer and Lin Salamo

with Harriet Elinor Smith

and the late Walter Blair

A publication of the

Mark Twain Project of The Bancroft Library

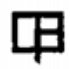

University of California Press

Berkeley

Los Angeles

London 
The text of this Mark Twain Library edition of Adventures of Huckleberry Finn is identical with the text of the scholarly edition of Adventures of Huckleberry Finn, edited by Victor Fischer and Lin Salamo (University of California Press, 2003). It is based on the complete author's manuscript now in the Buffalo and Erie County Public Library, and was established in accord with the standards of the Committee on Scholarly Editions (CSE). Editorial work was supported by generous grants from the Barkley Fund, the Hedco Foundation, and the National Endowment for the Humanities.

University of California Press, one of the most distinguished university presses in the United States, enriches lives around the world by advancing scholarship in the humanities, social sciences, and natural sciences. Its activities are supported by the UC Press Foundation and by philanthropic contributions from individuals and institutions. For more information, visit www.ucpress.edu.

University of California Press Berkeley and Los Angeles, California

University of California Press, Ltd. London, England

All previously unpublished material by Mark Twain (C) 1985, 1988, 1995, 1996, and 2001 by Richard A. Watson and Chase Manhattan Bank as Trustees of the Mark Twain Foundation, which reserves all reproduction or dramatization rights in every medium. This text of Adventures of Hucklebemy Finn, correctly established for the first time from the complete manuscript and other authoritative documents, as well as the editorial foreword, maps, explanatory notes, glossary, documentary appendixes, and note on the text (c) 1985, 2001, and 2010 by The Regents of the University of California. ISBN 978-0-520-26610-0 (pbk.: alk. paper)
The Library of Congress has cataloged an earlier edition of this book as follows:

\section{Library of Congress Cataloging-in- Publication Data}

Twain, Mark, 1835-1910.

Adventures of Huckleberry Finn / Mark Twain ; illustrated by E. W. Kemble and John Harley ; editors, Victor Fischer... [et al.].

p. cm.-(The Mark Twain Library)

"A publication of the Mark Twain Project of the Bancroft Library."

Includes bibliographical references (p. ). ISBN 978-0-520-22838-2 (pbk. : alk. paper)

1.' Finn, Huckleberry (Fictitious character)-Fiction. 2. Mississippi River-Fiction. 3. Fugitive slavesFiction. 4. Male friendship-Fiction. 5. Missouri-Fiction. 6. Boys-Fiction. 1. Fischer, Victor, 1942- II. Bancroft Library. III. Title.

PS1305.A2 F5 2001

813'.4-dc21

2001027448

Manufactured in the United States of America
$\begin{array}{llll}19 & 18 & 17 & 16\end{array}$
$\begin{array}{llllll}10 & 9 & 8 & 7 & 6 & 5\end{array}$

The paper used in this publication meets the minimum requirements of ANSI/NISO 239.48 . 1992 (R 1997) (Permanence of Paper).

The Mark Twain Library is designed by Steve Renick. 
The text of this Mark Twain Library edition of

Adventures of Huckleberry Finn is drawn from the Mark Twain Project's complete edition of

The Works and Papers of Mark Twain.

Editorial work for this volume has been supported by grants to the Friends of The Bancroft Library from the

\author{
BARKLEY FUND \\ and the \\ HEDCO FOUNDATION
}

\begin{abstract}
and by matching funds from the
NATIONAL ENDOWMENT FOR THE HUMANITIES,

an independent federal agency.
\end{abstract}

Without such generous support, these editions could

not have been produced. 

The Mark Twain Project

dedicates this volume to

WALTER BLAIR

in appreciation of his contributions

to the field of Mark Twain studies

and also to the

TEACHERS OF AMERICAN LITERATURE

who have continued to find new ways

to bring Huckleberry Finn alive

in their classrooms. 
